\title{
Temperature and Humidity Control in Greenhouses in Desert Areas
}

\author{
Shigeki Hirasawa*, Mai Nakatsuka, Kunio Masui, Tsuyoshi Kawanami, Katsuaki Shirai \\ Department of Mechanical Engineering, Kobe University, Kobe, Japan \\ Email: ${ }^{*}$ irasawa@kobe-u.ac.jp
}

Received 5 October 2014; revised 1 November 2014; accepted 14 November 2014

Copyright (C) 2014 by authors and Scientific Research Publishing Inc.

This work is licensed under the Creative Commons Attribution International License (CC BY). http://creativecommons.org/licenses/by/4.0/

c) (i) Open Access

\begin{abstract}
Water consumption can be reduced by using a greenhouse for agriculture in desert areas. We analyzed the effect of control of ventilation, sprinkler water, and solar radiation shielding on changes of temperature and humidity in a greenhouse under various desert area conditions. We calculated the changes in temperature and humidity in a greenhouse for a whole day in four seasons, and the calculation results of water consumption with and without a greenhouse were compared. When ventilation, shielding, and sprinkler water were controlled under suitable conditions to grow orchids in a desert area, water consumption in July was only $7 \%$ of that without a greenhouse.
\end{abstract}

\section{Keywords}

Temperature Control, Humidity, Ventilation, Sprinkler Water, Heat Transfer, Greenhouse, Desert

\section{Introduction}

Irrigation and agriculture in desert areas, such as the Middle East, have been executed successfully. Water consumption can be reduced by using a greenhouse in a desert area because most evaporated water can be confined to the greenhouse. Therefore, agriculture using greenhouses is a good approach in desert areas. However, changes in temperature and humidity in greenhouses are not preferable for growth of plants without control. Therefore, control of temperature and humidity by ventilation, sprinkler water, and solar radiation shielding is indispensable for agriculture using greenhouses in desert areas.

Some studies on the control of temperature and humidity in a greenhouse and agriculture at desert have been reported. Fahmy et al. [1] developed a control technique using an evaporative cooling system to improve the temperature and humidity conditions in a greenhouse and reported a calculation model based on MATLAB.

${ }^{*}$ Corresponding author. 
Temperature and humidity in a greenhouse were controlled to fix at the optimal values for growing of herb by adjusting air flow rate of the fan and adding moisture to the air using a PI (proportional integral) control. Ishii et al. [2] measured the effect of circulating fans on air flow and temperature distribution in a greenhouse and reported how airflow and temperature distribution were influenced by the number and position of the fans. Hattori et al. [3] analyzed the temperature distribution in a greenhouse with a circulating fan using a 3-dimensional computational thermo-fluid dynamics code and compared the experimental results. Tanaka and Ishii [4] experimentally studied the effect of a roof absorber that absorbs infrared rays on thermal environment control in a greenhouse. Nagler et al. [5] proposed an evaporation model at a semiarid rangeland. Bruin et al. [6] reported a model of water evaporation and heat transfer at the surface of land. However, there have been few studies on the control of temperature and humidity in a greenhouse in desert areas.

In this work, we analyzed the effect of control of ventilation, sprinkler water and solar radiation shielding on transient changes in temperature and humidity in a greenhouse in a desert area. We calculated the effect of reducing of water consumption by using a greenhouse to grow orchids.

\section{Calculation Method}

The calculation model of temperature and humidity in a greenhouse in a desert area is shown in Figure 1. Temperature and humidity in the green house were controlled by air ventilation, sprinkler water on the sand, and solar radiation shielding on the roof. Radiation, convection, evaporation, and conduction heat transfer in the calculation model are shown in Figure 1. The greenhouse was $10 \mathrm{~m} \times 30 \mathrm{~m} \times 2.5 \mathrm{~m}$ (in height), and the wall and roof were glass. We assumed that the temperature of the sand at a $150 \mathrm{~mm}$ depth was constant for all days and water loss by permeation into the sand was negligible. Orchids were planted with a $0.3 \mathrm{~m}$ pitch in the greenhouse. Sprinkler water was only present near the roots of the plants. We used the surrounding air temperature, humidity, and solar radiation conditions in Riyadh, Saudi Arabia for sunny days on January 1, April 1, July 1, and October 1 [7]. The conditions to grow orchids in the greenhouse were assumed as follows. Average temperature for one day was approximately $15^{\circ} \mathrm{C}$ in January, $25^{\circ} \mathrm{C}$ in April, $30^{\circ} \mathrm{C}$ in July, and $25^{\circ} \mathrm{C}$ in October, and the relative humidity in the air was kept greater than $50 \%$ [8]. Dry portions were not allowed to occur in the sand near the roots of plants, and the amount of water that had evaporated from the sand was supplied to the roots of the plants when necessary.

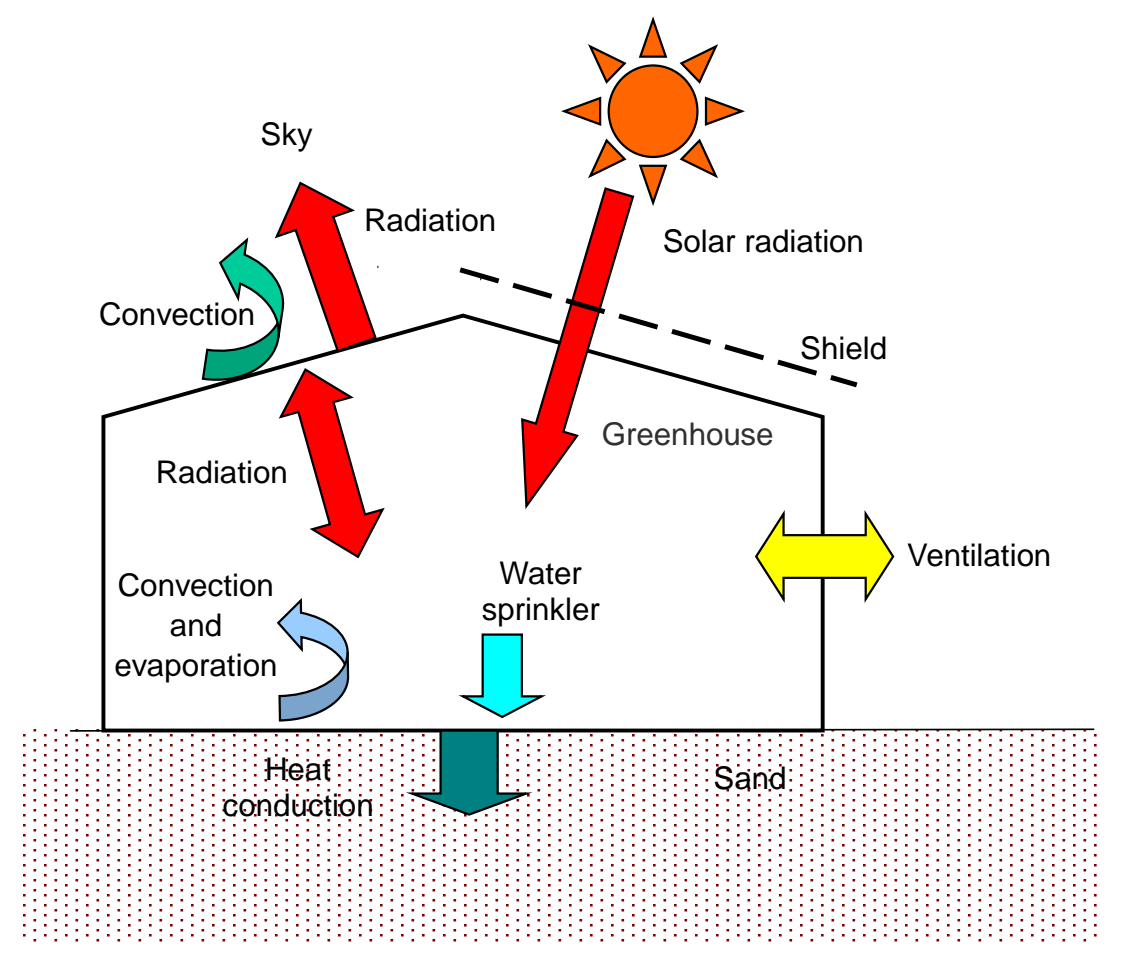

Figure 1. Calculation model. 
Changes in temperature $T\left({ }^{\circ} \mathrm{C}\right)$ and absolute humidity $X(\mathrm{~kg} / \mathrm{kg}$ (dry air)) in the greenhouse were calculated using the network method or the lumped model with the heat and mass balance [9]. The nodal points in the calculation were the surface of the sand near the roots of plants (temperature $T_{\mathrm{s} 1}$ and absolute humidity $X_{\mathrm{s} 1}$ ), surface of the sand at a place far from the roots (temperature $T_{\mathrm{s} 2}$ and absolute humidity $X_{\mathrm{s} 2}$ ), air in the greenhouse (average temperature $T_{\text {in }}$ and absolute humidity $X_{\text {in }}$ ), and wall of the greenhouse (temperature $T_{\text {gls }}$ and absolute humidity $X_{\mathrm{gls}}$ ) for the surrounding air (temperature $T_{\text {out }}$ and absolute humidity $X_{\text {out }}$ ), sky temperature $T_{\text {ten }}$, and solar radiation $q_{\mathrm{s}}$.

The equation of heat balance of the node at the surface of the sand $(k=1$ and 2$)$ is:

$$
\rho_{\mathrm{s}} C_{\mathrm{s}} \frac{V_{\mathrm{sk}}}{A_{\mathrm{sk}}} \frac{\mathrm{d} T_{\mathrm{sk}}}{\mathrm{d} t}=q_{\mathrm{s}}\left(1-A_{\mathrm{sya}}\right) a_{\mathrm{s}} a_{\mathrm{gls}}-\frac{\lambda_{\mathrm{s}}}{h_{\mathrm{s}}}\left(T_{\mathrm{sk}}-T_{\text {ave }}\right)-\alpha_{\mathrm{si}}\left(T_{\mathrm{sk}}-T_{\mathrm{in}}\right)-\rho_{\mathrm{w}} L_{\mathrm{w}} M_{\mathrm{si}}\left(X_{\mathrm{sk}}-X_{\mathrm{in}}\right)-\alpha_{\mathrm{sg}}\left(T_{\mathrm{sk}}-T_{\mathrm{gls}}\right)
$$

Here, $\rho_{\mathrm{s}}$ is the density of the sand $\left(\rho_{\mathrm{s}}=1500 \mathrm{~kg} / \mathrm{m}^{3}\right), C_{\mathrm{s}}$ is the specific heat capacity of the sand $\left(C_{\mathrm{s}}=1100\right.$ $\mathrm{J} / \mathrm{kg} \mathrm{K}), V_{\mathrm{sk}}$ is the volume of the surface node of the sand $\left(\left(V_{\mathrm{sk}} / A_{\mathrm{sk}}\right)=\left(h_{\mathrm{s}} / 2\right)\right), A_{\mathrm{sk}}$ is the surface area of the sand for near the roots and a place far from the root ( $k=1$ and 2$), h_{\mathrm{s}}$ is the depth of the sand $\left(h_{\mathrm{s}}=0.15 \mathrm{~m}\right), t$ is the time, $q_{\mathrm{s}}$ is the solar radiation heat flux on unit surface area, $A_{\text {sya }}$ is the shielding ratio of the roof, $a_{\mathrm{s}}$ is the absorptivity of the sand ( $\left.a_{\mathrm{s}}=1\right), a_{\mathrm{gls}}$ is the transmissivity of the roof $\left(a_{\mathrm{gls}}=0.7\right), \lambda_{\mathrm{s}}$ is the thermal conduction coefficient of sand with water ( $\lambda_{\mathrm{s}}=1.1 \mathrm{~W} / \mathrm{m} \mathrm{K}$ ), $T_{\text {ave }}$ is the temperature of sand at depth $h_{\mathrm{s}}=0.15 \mathrm{~m}$, which is the average temperature of the surrounding air temperature $T_{\text {out }}$ for one day, $\alpha_{\mathrm{si}}$ is the convection heat transfer coefficient on the surface of the sand $\left(\alpha_{\mathrm{si}}=3 \mathrm{~W} / \mathrm{m}^{2} \mathrm{~K}\right), M_{\mathrm{si}}$ is the mass heat transfer coefficient at the surface of the sand $\left(M_{\mathrm{si}}=\right.$ $\alpha_{\mathrm{s}}\left(\rho_{\mathrm{w}} C_{\mathrm{w}}\right)=7 \times 10^{-7} \mathrm{~m} / \mathrm{s}$, which is obtained assuming the Lewis number is 1$), \rho_{\mathrm{w}}$ is the density of water, $C_{\mathrm{w}}$ is the specific heat capacity of water, $L_{\mathrm{w}}$ is the latent heat of water $\left(L_{\mathrm{w}}=2.4 \times 10^{6} \mathrm{~J} / \mathrm{kg}\right)$, and $\alpha_{\mathrm{sg}}$ is the equivalent radiation heat transfer coefficient between the surface of the sand and the inside wall of the greenhouse $\left(\alpha_{\mathrm{sg}}=3\right.$ $\left.\mathrm{W} / \mathrm{m}^{2} \mathrm{~K}\right)$.

The equation of heat balance of the node of air in the greenhouse is:

$$
\rho_{\mathrm{a}} C_{\mathrm{a}} V_{\mathrm{air}}\left(T_{\text {in }}-T_{\text {out }}\right)=\alpha_{\mathrm{si}}\left(T_{\mathrm{s} 1}-T_{\text {in }}\right) A_{\mathrm{s} 1}+\alpha_{\mathrm{si}}\left(T_{\mathrm{s} 2}-T_{\text {in }}\right) A_{\mathrm{s} 2}+\alpha_{\mathrm{gi}}\left(T_{\text {gls }}-T_{\text {in }}\right) A_{\text {gls }}
$$

Here, $\alpha_{\mathrm{gi}}$ is the convection heat transfer coefficient on the inside wall of the greenhouse $\left(\alpha_{\mathrm{gi}}=3 \mathrm{~W} / \mathrm{m}^{2} \mathrm{~K}\right), A_{\mathrm{gls}}$ is surface area of the wall of the greenhouse, $\rho_{\mathrm{a}}$ is the density of air, $C_{\mathrm{a}}$ is the specific heat capacity of air, and $V_{\text {air }}$ is the air ventilation volume $\left(\mathrm{m}^{3} / \mathrm{s}\right)$. Heat capacity of the wall of the greenhouse was neglected in Equation (2).

The equation of water mass balance of the node of air in the greenhouse is:

$$
V_{\text {air }}\left(X_{\text {in }}-X_{\text {out }}\right)=M_{\mathrm{si}}\left(X_{\mathrm{s} 1}-X_{\text {in }}\right) A_{\mathrm{s} 1}+M_{\mathrm{si}}\left(X_{\mathrm{s} 2}-X_{\text {in }}\right) A_{\mathrm{s} 2}+M_{\mathrm{gi}}\left(X_{\mathrm{gls}}-X_{\mathrm{s}}\right) A_{\mathrm{gls}}
$$

Here, $M_{\mathrm{gi}}$ is the mass heat transfer coefficient at the surface of the inside wall of the greenhouse $\left(M_{\mathrm{gi}}=7 \times\right.$ $10^{-7} \mathrm{~m} / \mathrm{s}$ ). The absolute humidity near the surface of the sand and the wall of the greenhouse $X_{\mathrm{s}}$ and $X_{\mathrm{gls}}$ were obtained from temperature $T_{\mathrm{s}}$ and $T_{\mathrm{gls}}$ assuming the satisfied condition.

The equation of heat balance of the node at the wall of the greenhouse is:

$$
\begin{aligned}
& -\alpha_{\mathrm{st}}\left(T_{\mathrm{gls}}-T_{\mathrm{ten}}\right) A_{\mathrm{gls}}-\alpha_{\mathrm{sg}}\left(T_{\mathrm{gls}}-T_{\mathrm{s} 1}\right) A_{\mathrm{s} 1}-\alpha_{\mathrm{sg}}\left(T_{\mathrm{gls}}-T_{\mathrm{s} 2}\right) A_{\mathrm{s} 2}-\alpha_{\mathrm{gi}}\left(T_{\mathrm{gls}}-T_{\mathrm{in}}\right) A_{\mathrm{gls}} \\
& -\alpha_{\mathrm{go}}\left(T_{\mathrm{gls}}-T_{\mathrm{out}}\right) A_{\mathrm{gls}}+\rho_{\mathrm{w}} L_{\mathrm{w}} M_{\mathrm{gi}}\left(X_{\mathrm{gls}}-X_{\mathrm{s}}\right) A_{\mathrm{gls}}=0
\end{aligned}
$$

Here, $\alpha_{\mathrm{st}}$ is the equivalent radiation heat transfer coefficient between the sky and the outside wall of the greenhouse $\left(\alpha_{\mathrm{st}}=3 \mathrm{~W} / \mathrm{m}^{2} \mathrm{~K}\right)$, and $\alpha_{\mathrm{go}}$ is the convection heat transfer coefficient on the outside wall of the greenhouse $\left(\alpha_{\mathrm{go}}=3 \mathrm{~W} / \mathrm{m}^{2} \mathrm{~K}\right)$. The sky temperature $T_{\text {ten }}$ was calculated using an equation proposed by Swinbank [10], which is a function of the surrounding air temperature $T_{\text {out }}$.

Equations (1)-(4) were calculated by the implicit finite-difference method with a calculation time step of 3 hours.

\section{Calculation Results of Effect of Parameters}

We calculated the effect of control of ventilation and shielding on temperature and humidity in a greenhouse under typical conditions at noon on October 1. Figure 2 and Figure 3 show the calculation results of the effect 


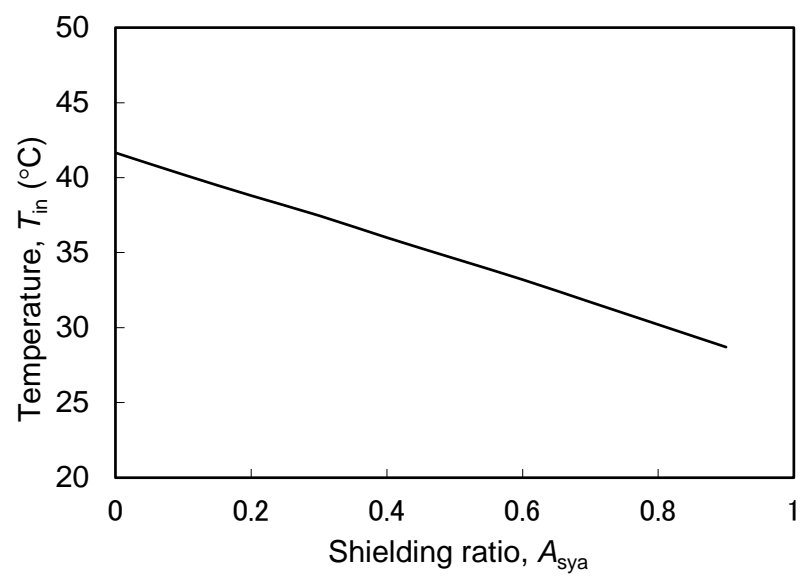

Figure 2. Effect of shielding ratio on temperature in greenhouse.

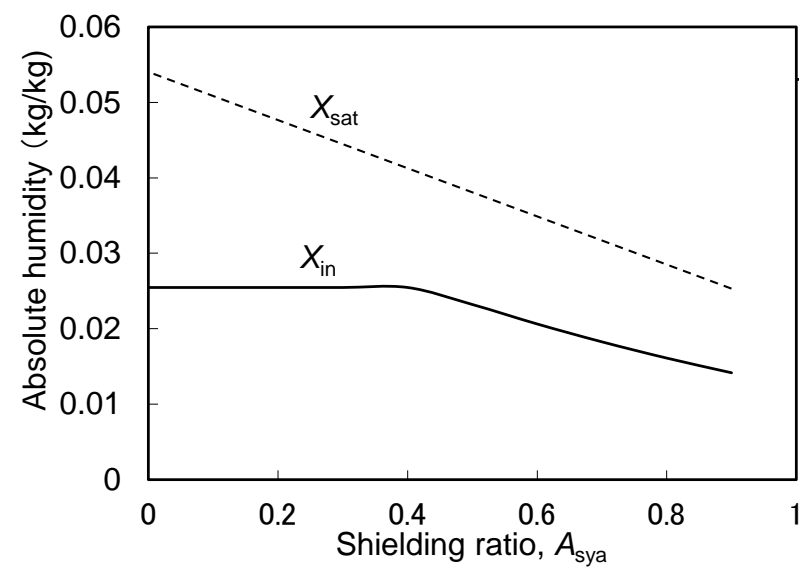

Figure 3. Effect of shielding ratio on absolute humidity in greenhouse.

of shielding ratio of the roof $A_{\text {sya }}$ on the temperature $T_{\text {in }}$ and absolute humidity $X_{\text {in }}$ in the greenhouse for the condition of ventilation $V_{\text {air }}=0.2 \mathrm{~m}^{3} / \mathrm{s}$. The saturated humidity $X_{\text {sat }}$ in relation to temperature $T_{\text {in }}$ is also shown in Figure 3. The relative humidity $\varphi$ is defined as $\varphi=X_{\text {in }} / X_{\text {sat. }}$ The temperature in the greenhouse decreases linearly in according with the shielding ratio of the roof. The relative humidity in the greenhouse is maximum when $A_{\text {sya }}=0.4$ because the absolute humidity $X_{\text {in }}$ is almost constant when $A_{\text {sya }}$ is less than 0.4 , and the absolute humidity $X_{\text {in }}$ decreases when $A_{\text {sya }}$ is more than 0.4 . Figure 4 shows the effect of shielding ratio on total water usage in one day. The curve of total water usage in one day is similar to that of the absolute humidity $X_{\text {in }}$ in Figure 3.

Figure 5 and Figure 6 show the calculation results of the effect of ventilation $V_{\text {air }}$ on the temperature $T_{\text {in }}$, absolute humidity $X_{\text {in }}$ in the greenhouse and saturated humidity $X_{\text {sat }}$ in relation to temperature $T_{\text {in }}$ for the condition of shielding ratio $A_{\text {sya }}=0$. The absolute humidity in the greenhouse decreases when ventilation $V_{\text {air }}$ is larger than $1 \mathrm{~m}^{3} / \mathrm{s}$. Figure 7 shows the effect of ventilation on total water usage in one day. The total water usage in one day increases when ventilation $V_{\text {air }}$ is larger than $1 \mathrm{~m}^{3} / \mathrm{s}$. The value of the total water usage in one day with the effect of ventilation $V_{\text {air }}$ in Figure 7 is about 10 times that with the effect of shielding ratio $A_{\text {sya }}$ in Figure 4.

\section{Calculation Results of Effect of Greenhouse to Grow Orchids in Desert}

We calculated the change in temperature and absolute humidity every 3 hours under the conditions in Saudi Arabia. Figure 8 shows the total water usage in one day without a greenhouse to grow orchids in the desert on October 1, January 1, April 1, and July 1. Dry portions were not allowed to occur in the sand near the roots of the plants at any time, and the amount of evaporated water from the sand was supplied to the roots of the plants. 


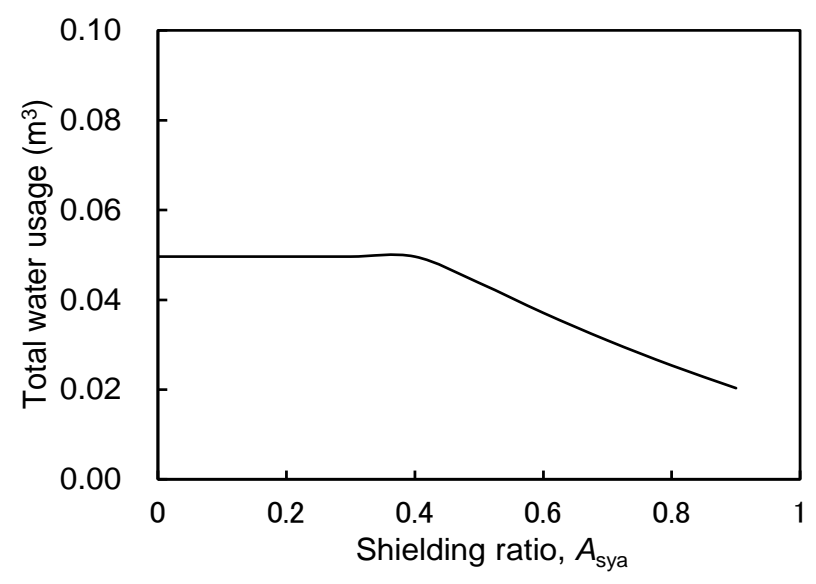

Figure 4. Effect of shielding ratio on total water usage in one day.

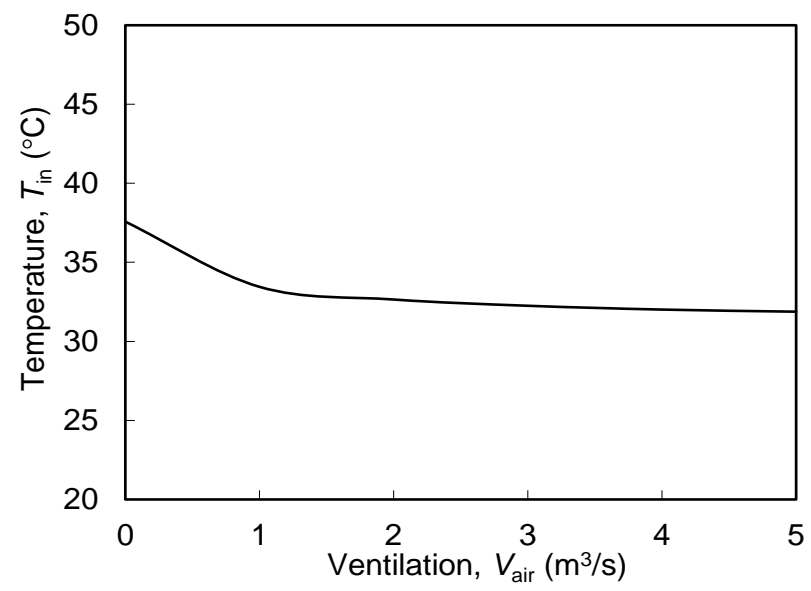

Figure 5. Effect of ventilation on temperature in greenhouse.

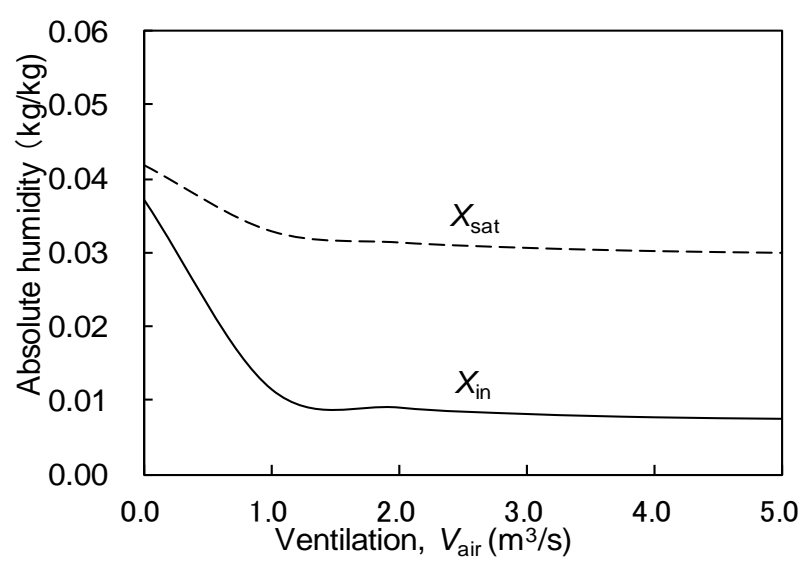

Figure 6. Effect of ventilation on absolute humidity in greenhouse.

The total water usage in one day in July is $3.8 \mathrm{~m}^{3}$, which is 3 times that in January.

Figure 9 shows the total water usage in one day with a greenhouse to grow orchids in the desert on October 1 , January 1, April 1, and July 1. Ventilation, solar radiation shielding and sprinkler water were controlled so that the average temperature for one day and relative humidity were near the specified conditions (as explained 


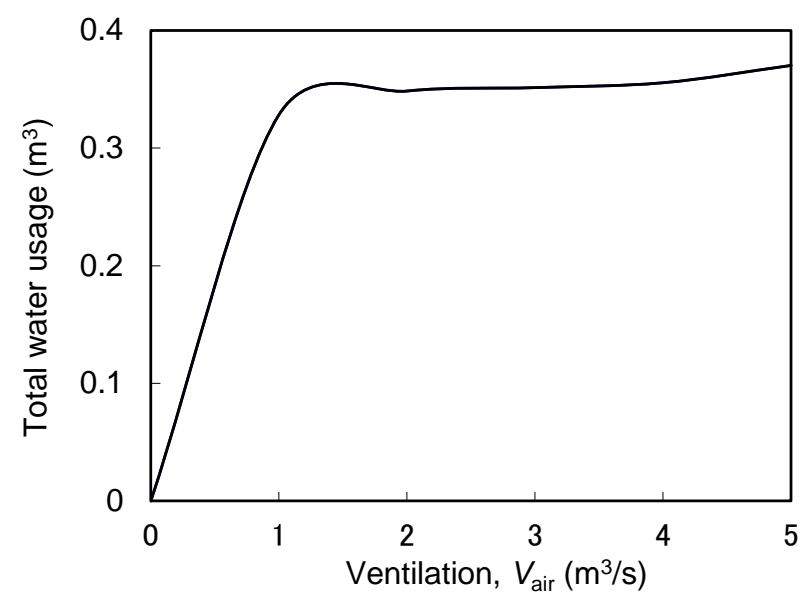

Figure 7. Effect of ventilation on total water usage in one day.

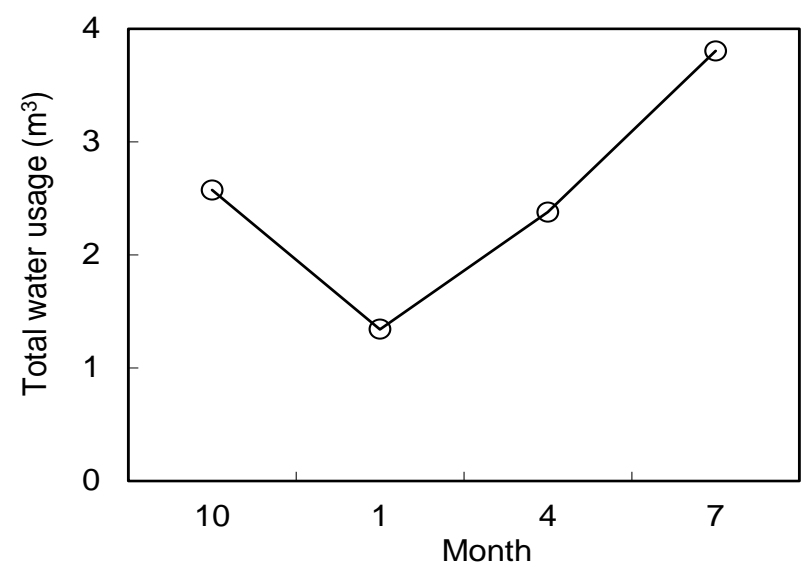

Figure 8. Total water usage in one day without greenhouse.

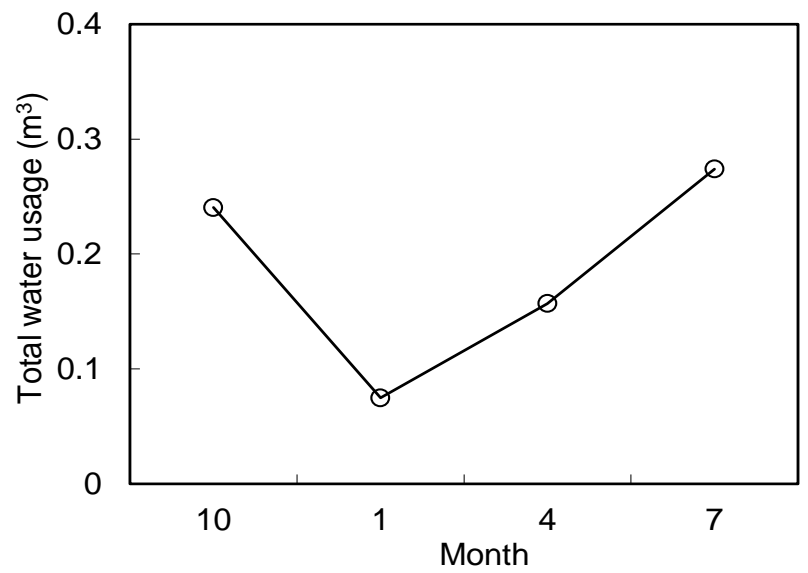

Figure 9. Total water usage in one day with greenhouse.

above). The total water usage in one day in July is $0.3 \mathrm{~m}^{3}$, which is only $7 \%$ of that without a greenhouse. Figure 10 shows the change in ventilation and shielding ratio used in the calculation for October. Figure 11 shows the change of water supply rate. Figure 12 shows the calculation results of the change in temperature in the greenhouse $T_{\mathrm{in}}$, sand near roots of plant $T_{\mathrm{s} 1}$, and surrounding air $T_{\text {out }}$ in October. The temperature in the greenhouse $T_{\text {in }}$ is close to the temperature of surrounding air $T_{\text {out }}$ due to the control. Figure 13 shows the change of absolute 


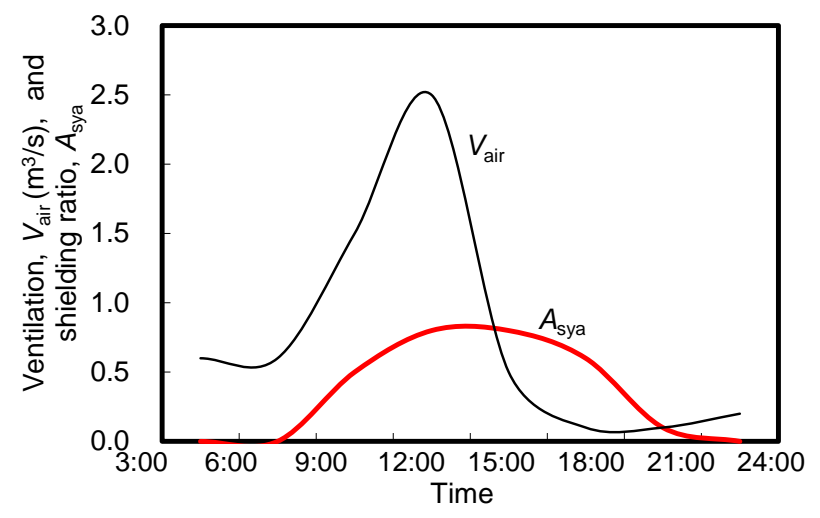

Figure 10. Change of ventilation and shielding ratio in October.

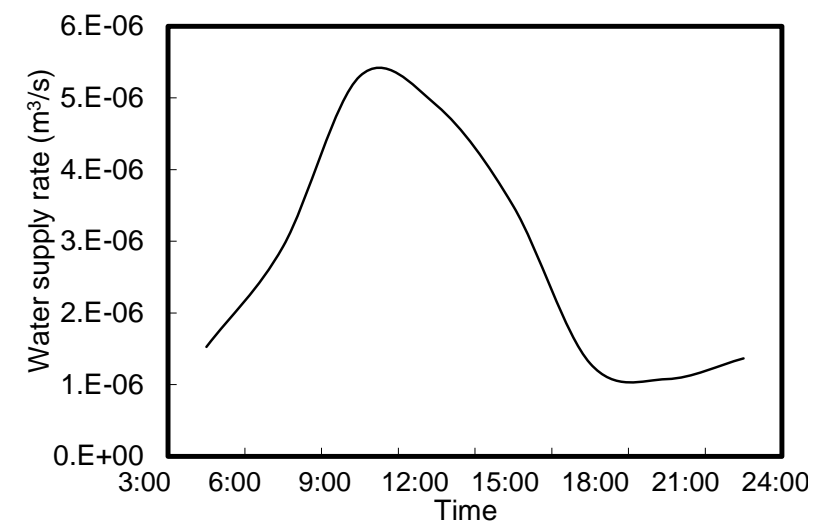

Figure 11. Change of water supply rate in October.

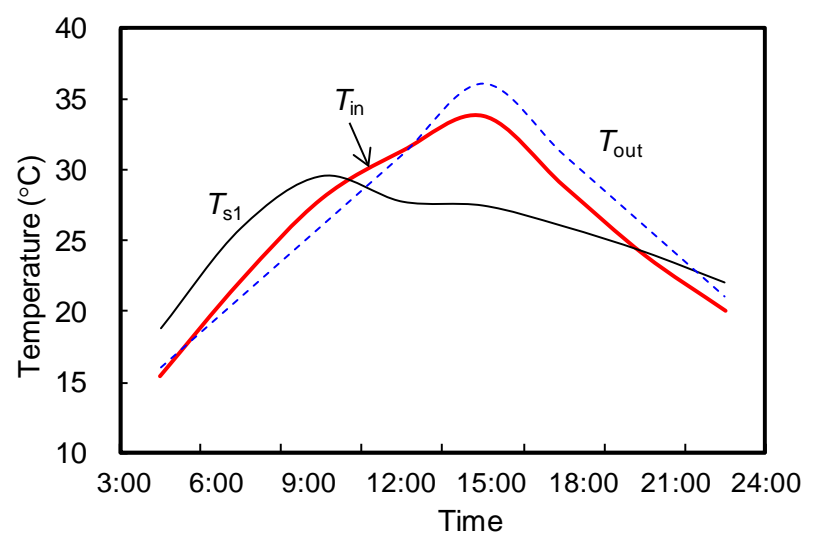

Figure 12. Change of temperature in greenhouse and sand air in October.

humidity in the greenhouse $X_{\text {in }}$ and saturated humidity $X_{\text {sat }}$ in accordance with temperature $T_{\mathrm{in}}$. The relative humidity can be calculated with $\varphi=X_{\text {in }} / X_{\text {sat }}$. The absolute humidity in the greenhouse is almost constant.

Therefore water consumption can be reduced very much by using greenhouses for agriculture in desert areas with an optimum control of ventilation, sprinkler water, and shielding solar radiation according to this work.

\section{Summary}

We analyzed the effect of control of ventilation, sprinkler water, and solar radiation shielding on transient 


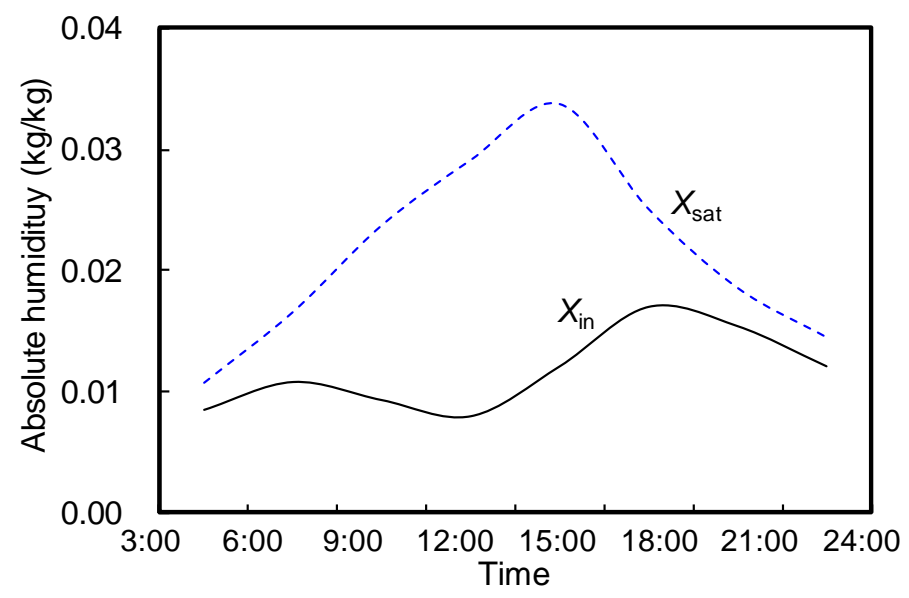

Figure 13. Change of absolute humidity in greenhouse in October.

changes in temperature and humidity in a greenhouse in a desert area, and the following results were obtained.

1) The temperature in the greenhouse decreased in accordance with the shielding ratio of solar radiation. The relative humidity in the greenhouse was maximum when the shielding ratio was 0.4 .

2) The relative humidity in the greenhouse decreased when the ventilation was larger than $1 \mathrm{~m}^{3} / \mathrm{s}$. The total water usage in one day increased when the ventilation was larger than $1 \mathrm{~m}^{3} / \mathrm{s}$.

3) When ventilation, shielding, and sprinkler water were controlled under suitable conditions to grow orchids, water consumption in July was only $7 \%$ of that without a greenhouse.

\section{References}

[1] Fahmy, F.H., Farghally, H.M., Ahmed, N.M. and Nafeh, A.A. (2012) Modeling and Simulation of Evaporative Cooling System in Controlled Environment Greenhouse. Smart Grid and Renewable Energy, 3, 67-71. http://dx.doi.org/10.4236/sgre.2012.31010

[2] Ishii, M., Okushima, L., Moriyama, H. and Furihata, Y. (2012) Influence of Circulation Fans on the distribution of Air Temperature and Air velocity in a Greenhouse. Journal of Science and High Technology in Agriculture, 24, $193-200$. http://dx.doi.org/10.2525/shita.24.193

[3] Hattori, K., Ito, K., Akashi, Y., Nakagawa, H. and Hayashi, T. (2010) Field Measurement and Numerical Prediction ofAirflow and Temperature Distributionin Large Scale Green House. Transaction of the Society of Heating, Air-Conditioning Sanitary Engineers of Japan, 162, 25-34.

[4] Tanaka, I. and Ishii, Y. (1988) A Fundamental Study on the Thermal Environment Control in a Greenhouse by the Roof Absorber of Infrared Rays. Research Bulletin of the Faculty College of Agriculture Gifu University, 53, 159-165.

[5] Nagler, P.L., Glenn, E.P., Kim, H., Emmerich, W., Scott, R.L., Huxman, T.E. and Huete, A.R. (2007) Relationship between Evapotranspiration and Precipitation Pulses in a Semiarid Rangeland Estimated by Moisture Flux Towers and MODIS Vegetation Iindices. Journal of Arid Environments, 70, 443-462. http://dx.doi.org/10.1016/j.jaridenv.2006.12.026

[6] Bruin, H.A.R., Kohsiek, W. and Van den Hurk, B.J.J.M. (1993) A Verification of Some Methods to Determine the Fluxes of Momentum, Sensible Heat, and Water Vapor using Standard Deviation and Structure Parameter of Scalar Meteorological Quantities. Boundary-Layer Meteorology, 63, 231-257. http://dx.doi.org/10.1007/BF00710461

[7] National Astronomical Observatory of Japan (2014) Chronological Scientific Table ("Rika Nenpho” in Japanese). Maruzen Publishing Co., Ltd., Tokyo.

[8] Mihara, Y. (1972) Climate Control in Plantation ("Shisetsu Engei no Kikou Kanri” in Japanese), Seibundo Shinkosha Publishing Co., Ltd., Tokyo.

[9] Campbell, G.S. (1985) Soil Physics with BASIC—-Transport Models for Soil-Plant Systems. Elsevier Co., Amsterdam.

[10] Swinbank, W.C. (1963) Long-Wave Radiation from Clear Skies. Quarterly Journal of the Royal Meteorological Society, 89, 339-348. http://dx.doi.org/10.1002/qj.49708938105 
Scientific Research Publishing (SCIRP) is one of the largest Open Access journal publishers. It is currently publishing more than 200 open access, online, peer-reviewed journals covering a wide range of academic disciplines. SCIRP serves the worldwide academic communities and contributes to the progress and application of science with its publication.

Other selected journals from SCIRP are listed as below. Submit your manuscript to us via either submit@scirp.org or Online Submission Portal.
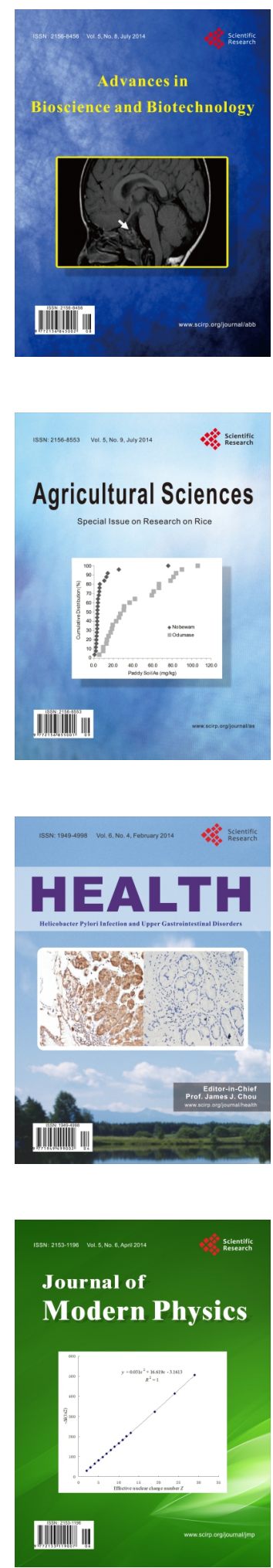
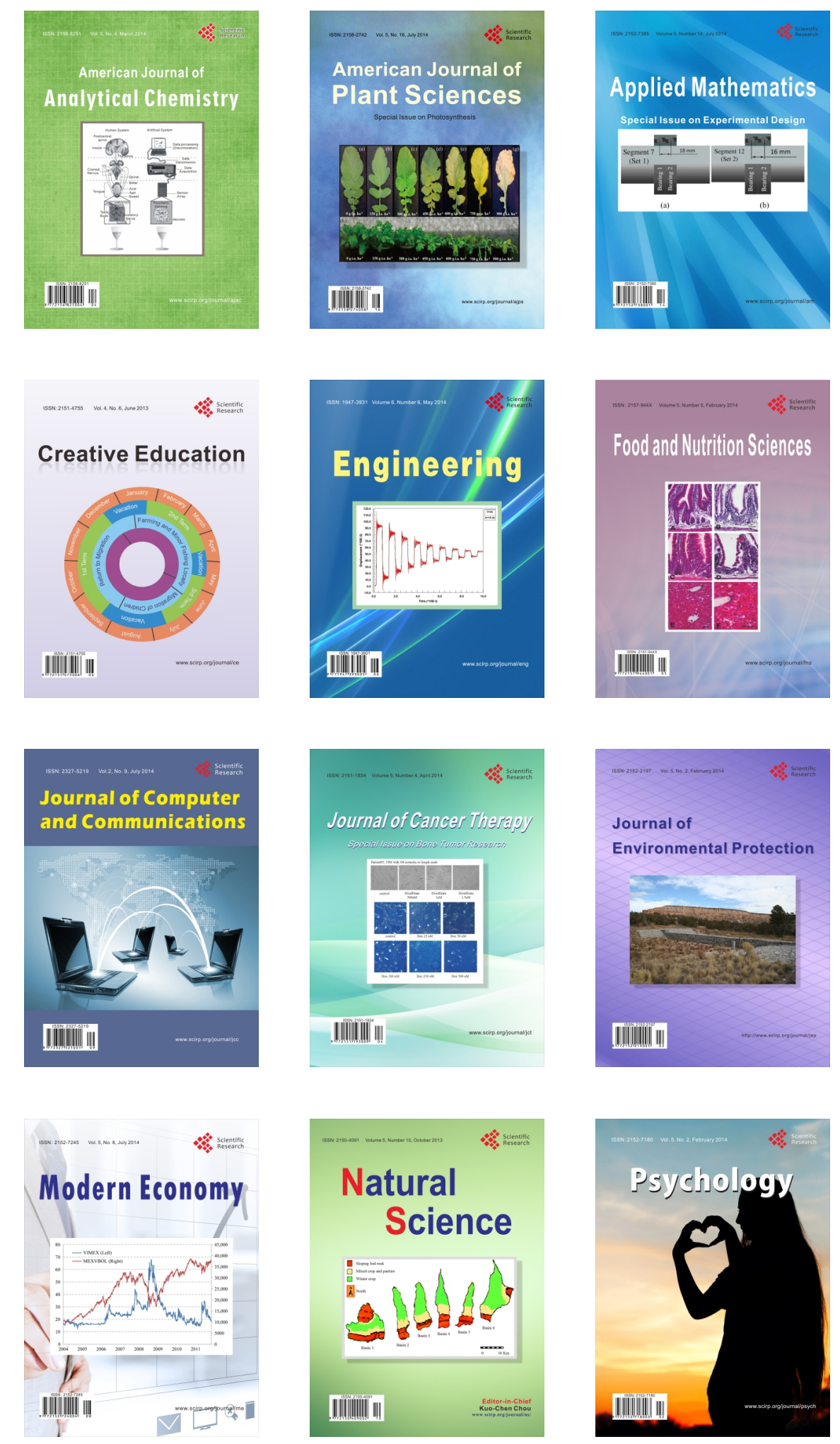